\title{
WT1-pulsed Dendritic Cell Vaccine Combined with Chemotherapy for Resected Pancreatic Cancer in a Phase I Study
}

\author{
RYU YANAGISAWA ${ }^{1}$, TOMONOBU KOIZUMI ${ }^{2}$, TERUTSUGU KOYA ${ }^{3}$, KENJI SANO ${ }^{4}$, \\ SHIGEO KOIDO ${ }^{5}, \mathrm{KAZUHIRO} \mathrm{NAGAI}^{6}$, MASANORI KOBAYASHI $^{7}$, \\ MASATO OKAMOTO $^{7}$, HARUO SUGIYAMA $^{8}$ and SHIGETAKA SHIMODAIRA ${ }^{3}$ \\ ${ }^{1}$ Center for Advanced Cell Therapy, ${ }^{2}$ Shinshu Cancer Center, and \\ ${ }^{4}$ Department of Laboratory Medicine, Shinshu University Hospital, Matsumoto, Japan; \\ ${ }^{3}$ Department of Regenerative Medicine, Kanazawa Medical University, Ishikawa, Japan; \\ ${ }^{5}$ Department of Gastroenterology and Hepatology, The Jikei University School of Medicine, Kashiwa, Japan; \\ ${ }^{6}$ Transfusion and Cell Therapy Unit, Nagasaki University Hospital, Sakamoto, Japan; \\ ${ }^{7}$ Department of Advanced Immunotherapeutics, \\ Osaka University Graduate School of Pharmaceutical Sciences, Suita, Japan; \\ ${ }^{8}$ Department of Functional Diagnostic Science, Graduate School of Medicine, Osaka University, Suita, Japan
}

\begin{abstract}
Background/Aim: Wilms' tumor 1 (WT1) is a tumor-associated antigen highly expressed in cancer. We examined the safety of WT1-peptide pulsed dendritic cell (WT1-DC) vaccine in combination with chemotherapy in patients with surgically resected pancreatic cancer. Patients and Methods: Eight patients with resectable pancreatic cancer undergoing surgery either combined with $S-1$ or S-1 plus gemcitabine therapy were enrolled. Immunohistochemical analysis of WT1 was performed in 34 cases of pancreatic cancer. Results: No serious side-effects were observed, except grade I fever in five and grade I reactions at the injection site in all patients. WT1-specific cytotoxic T-lymphocytes were detected in seven patients, and WT1 and human leukocyte antigen class I antigens were positive in all 34 cases. Conclusion: Our study clarified the safety and potential acquisition of immunity after vaccination targeting WT1. Further efficacy of WTI-DC vaccine to improve prognosis would be determined by a prospective clinical trial for resectable pancreatic cancer.
\end{abstract}

This article is freely accessible online.

Correspondence to: Ryu Yanagisawa, M.D., Ph.D., Center for Advanced Cell Therapy, Shinshu University Hospital, 3-1-1, Asahi, Matsumoto 390-8621, Japan. Tel: +81 263373240, Fax: +81 263373027,e-mail: ryu@ shinshu-u.ac.jp

Key Words: DC vaccine, immunotherapy, S-1, T cell, WT1.
Although several treatment approaches, such as surgery and chemotherapy, have been used for treating pancreatic cancer, its prognosis remains poor, and further improvement in the treatment outcome is required (1-4). Recently, immunotherapy has been put forward as a new treatment approach for such cancer types with poor prognosis, and various methods have been examined in practice $(1,2,5-7)$. In immunotherapy, selection of the tumor-associated antigen (TAA) is important. It has been reported that the Wilms' tumor 1 (WT1) antigen is highly expressed in various malignancies (8), including pancreatic cancer $(8,9)$. Therefore, WT1 has been used as one of the targets of immunotherapy for pancreatic cancer $(1,7)$. For advanced pancreatic cancer, a WT1-peptide vaccine and WT1-peptide pulsed-dendritic cell (WT1-DC) vaccine have already been used in combination with chemotherapy agents, such as gemcitabine and S-1, in multiple studies, and its safety has been verified (10-16). Additionally, its clinical effects have been reported (11-13). Positive findings, such as WT1specific delayed-type hypersensitivity after administration of the WT1-DC vaccine, reduced neutrophil/lymphocyte ratio in peripheral blood before or after administration, increased expression of CD83/human leukocyte antigen (HLA)-DR on DCs after administration, and no increase in interleukin-6 levels in peripheral blood after administration, have been reported as prognostic factors $(13,15,16)$.

Acquired immunity responses to cancer antigens may not always be easily achievable; thus, concurrent use of adjuvants with WT1-DC vaccine is considered important. For example, montanide ISA51 is an adjuvant used in the 
treatment of cancer $(10,15)$. However, Hailemichael et al. reported that due to persisting vaccine depots induced by cancer peptide vaccines in incomplete Freund's adjuvant, montanide ISA51 could trigger specific T-cell sequestration, dysfunction, and deletion at the vaccination site (17). Picibanil (OK-432) has potent immunomodulation and therapeutic properties when used in cancer treatment as a biological response modifier (18). Several studies have demonstrated that $\mathrm{OK}-432$ induces the activation of a variety of effector cells, such as DCs, macrophages, natural killer cells, and cytotoxic T-lymphocytes (CTLs) (18-23). Furthermore, Hirayama et al. reported that OK-432 can inhibit the function of regulatory T-cells and contribute to activation of high-avidity tumor antigen-specific naive T-cell precursors (24). In fact, several studies have used OK-432 as an adjuvant for WT1-DC vaccine in patients with advanced pancreatic cancer $(11,12)$.

For patients diagnosed with primary pancreatic cancer, resection is the most important treatment, and implementation of postoperative chemotherapy can improve prognosis. In a recent report, the administration of S-1 alone was shown to be superior to that of gemcitabine for pancreatic cancer after resection (25). However, recurrence after surgery remains a serious problem. Therefore, the use of immunotherapy in combination with standard chemotherapy in the early phase can be considered as a strategy for the prevention of the recurrence of pancreatic cancer. Thus, in this study, we examined the safety of WT1-DC vaccine and acquisition of WT1-specific CTLs after administration of the vaccine with OK-432 as an adjuvant combined with chemotherapy (mainly S-1) in patients with surgically resected pancreatic cancer.

\section{Materials and Methods}

Patient selection. Between August 2013 and March 2016, patients with pancreatic cancer were consecutively enrolled in this study. During this period, patients with several types of cancer received the WT1-DC vaccine at the Center for Advanced Cell Therapy in Shinshu University Hospital (26). We selected those with pancreatic cancer who underwent resection after initial diagnosis and then received chemotherapy. We excluded patients who received chemotherapy before surgery. Other eligibility criteria have been previously described (27). The following competent standards were adhered to for DC therapy and eligibility: (I) Age, 20-70 years; (II) performance status, $0 / 1$; (III) normal organ function and absence of infectious disease, blood abnormality, and bleeding tendency; (IV) no history of cardiovascular disease or respiratory disorders tolerable for blood apheresis; (V) toleratant to chemotherapy and radiotherapy as standard cancer treatments; and (VI) diagnosed less than 6 months prior, or with recurrence of cancer sensitive to chemotherapy.

WT1-DC vaccine. The WT1-DC vaccine was prepared according to a previously reported method $(27,28)$. Briefly, we used HLAA*24:02-restricted WT1 (235-243:CYTWNQMNL), HLAA*02:01/02:06-restricted WT1 (126-134:RMFPNAPYL), and HLA class II-restricted peptides (332-347: KRYFKLSHLQMHSRKH) compatible with either DRB1*04:05, DRB1*08:03, DRB1*15:01, DRB1*15:02, DPB1*05:01, or DPB $1 * 09: 01$ according to the compatibility of each patient's HLA typing (27). WT1-DCs were

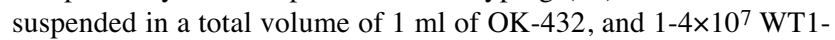
DCs were injected at each time according to the number of DCs in each case. The vaccine was intradermally and bilaterally administered near the axillary region and groin. As a course, it was administered seven times every 2 weeks. For OK-432, administration was initiated at a dose of 1 Klinische Einheit (KE; clinical unit) and increased to $2 \mathrm{KE}$ if no side-effects occurred.

Criteria of DC vaccine release. Flow cytometry was utilized to determine the antigenic profiles of mature DCs. Mature DCs were

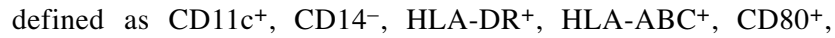
$\mathrm{CD} 3^{+}, \mathrm{CD} 86^{+}, \mathrm{CD} 40^{+}$, and $\mathrm{CCR} 7^{+}$cells. The following criteria were met for $\mathrm{DC}$ vaccine administration: purity (proportion of $\mathrm{CD} 11 \mathrm{c}^{+}, \mathrm{CD} 14^{-}, \mathrm{CD}^{2} 6^{+}, \mathrm{HLA}^{\left.-\mathrm{DR}^{+}\right)}>90 \%$; $>80 \%$ viability; mature DC phenotype; negative for bacterial and fungal infection after 14 days; endotoxin $\leq 0.05 \mathrm{EU} / \mathrm{ml}$; and negative for mycoplasma (27).

Evaluation of adverse events and clinical response. Safety evaluations were undertaken for the following: (I) allergic reactions post intradermal injection of DC vaccine (presence of reduced blood pressure, tachycardia, breathing difficulties, or rash); and (II) local reactions, fever, nausea, vomiting, diarrhea, appetite loss, mucosal ulcer, damage of the central nervous system, anemia, decreased white blood cell count, decreased platelet count, abnormal kidney function, or abnormal liver function during or after treatment completion (27). Adverse effects, including fever and skin reactions at the injection site, were monitored and graded according to the National Cancer Institute's Common Terminology Criteria for Adverse Events Version 4.0 (29). Fever and skin reactions at the injection site were examined after each vaccination in all patients. Reactions at the injection site were assessed after 24, 48, and $72 \mathrm{~h}$.

Evaluation of clinical response. We evaluated the duration of overall survival (OS) at 2 years post-surgery concomitant with the induction of WT1-specific CTLs during DC vaccination targeting WT1 in pancreatic cancer. We also utilized various imaging techniques (such as computed tomography and positron-emission tomography/ computed tomography) for the post-surgical assessment of lesions. The clinical response after administration of the WT1-DC vaccine was determined according to the evaluation method of the Response Evaluation Criteria in Solid Tumors (version 1.1) (RECIST v1.1) (30).

Evaluation of WT1-specific CTLs. Peripheral blood mononuclear cells were obtained before initiating the first vaccination and at the completion of the seventh vaccination. The phenotypes of circulating T-cell populations were determined through fluorescence-activated cell sorting by measuring the total $\mathrm{CD}^{+}$ population, $\mathrm{CD} 4^{+}$subpopulation, $\mathrm{CD} 8^{+}$subpopulation, activation markers HLA-DR on $\mathrm{CD}^{+}$cells, and other cell populations such as those of CD19-positive and CD56-positive cells. Enzyme-linked immunosorbent spot (ELISPOT) assays were performed using precoated human IFN- $\gamma$ ELISPOT PLUS kits (Mabtech, Nacka Strand, Sweden) to examine WT1-specific interferon (IFN)- $\gamma$ production by T-cells referred to as CTLs $(27,28)$. The WT1 tetramer assay was performed only in patients who received the HLA-A*24:02-restricted mutant WT1 peptide. WT1 tetramer was 
assessed in the CD3/CD8 double-positive population using WT1modified peptides/HLA-A*24:02 tetramers (MBL, Medical \& Biological Laboratories Co., Ltd., Nagoya, Japan) (27).

Immunohistochemical analysis of the primary tumor samples. We analyzed WT1, HLA-ABC, and epithelial membrane antigen (EMA) protein expressions in primary tumor samples using a previously described method (27). We used a mouse monoclonal antibody for WT1 (6F-H2; DakoCytomation, Carpinteria, CA, USA); HLA-ABC antigen (class I, W6/32; DakoCytomation); and EMA (Clone E29; DakoCytomation) for each analysis (27). In addition to this panel, we analyzed transporter associated with antigen processing (TAP) 1 using rabbit polyclonal anti-TAP1 (ADI-CSA-620-E; Enzo Life Sciences, Inc., Farmingdale, NY, USA). Expressions were determined as negative if positive tumor cells were $<25 \%, 1^{+}$if positive cells were from $25 \%$ to $50 \%, 2^{+}$if positive cells were from $50 \%$ to $75 \%$, and $3^{+}$if cells were $>75 \%$ (31). Along with samples from patients with resectable pancreatic cancer, we analyzed all available samples from patients with pancreatic cancer who received the WT1-DC vaccine at our institution.

Statistical analysis. We compared the results of ELISPOT and tetramer assays before and after administration of the WT1-DC vaccine using the Wilcoxon signed-rank test. We used a KaplanMeier curve to evaluate OS. All statistical analyses were performed using EZR (Saitama Medical Center, Jichi Medical University, Saitama, Japan) (32). Statistical significance was defined as a $p$-value of less than 0.05 .

Participants and ethics statement. The protocol followed for WT1DC vaccination therapy at the Shinshu University Hospital was approved by the Ethics Committee of Shinshu University School of Medicine (approval numbers 1123 and 1199). The Act on the Safety of Regenerative Medicine in Japan was enforced on November 25, 2014. Class III technologies are regarded as low risk since they use somatic cells with accumulated clinical experiences. The DC vaccination therapy (Class III technology) at the Shinshu University was approved on November 25, 2015 (approval numbers: PC3150643 and PC3150645). The application and conditions for WT1-DC vaccine therapy were approved under "Advanced Medical Care" in September 2012. We obtained written informed consent from all patients. All procedures performed in this study were in accordance with the Ethical Guidelines for Medical and Health Research involving Human Subjects proposed by the Ministry of Health, Labour and Welfare in Japan. http://www.mhlw.go.jp/ file/06-Seisakujouhou-10600000-Daijinkanboukouseikagakuka/ 0000080278.pdf (2015)].

\section{Results}

Patient characteristics. During the study period, the WT1DC vaccine was used for pancreatic cancer in a total of eight patients. Patient information is presented in Table I. Although commencement of WT1-DC vaccination after resection differed in each patient, $\mathrm{S}-1$ was commenced after resection as early as was feasible. Of the eight patients, seven received S-1 alone after surgery (combined with WT1DC vaccination) and one received a combination therapy of S-1 and gemcitabine. HLA compatibility was confirmed in six patients with HLA class I and class II. In the remaining two patients (patient 7 and 8), compatibility was noted for only the HLA class II peptide. The interval from surgical resection to apheresis of peripheral blood mononuclear cells ranged from 49 to 238 days (median=102.5 days). The interval from surgical resection to initial vaccine administration ranged from 105 to 261 days (median=153.5 days). All patients completed seven administrations of the WT1-DC vaccine. Furthermore, three out of the eight patients (patient 2, 3, and 8) repeated the second WT1-DC vaccine course. Although six out of the eight patients underwent S-1 chemotherapy treatment of at least 16 weeks (excluding rest periods), two of the eight patients discontinued S-1 treatment because of early recurrence (patient 7) and side-effects (pancytopenia; patient 5).

Adverse events of WT1-DC vaccine. Reactions at the injection site were observed in all eight patients, and all were grade I and reversible. Grade I fever was observed in five patients, and the fever quickly declined with only symptomatic treatment. No other adverse events were observed (Table II).

Clinical outcome. Of the eight patients, four died because of recurrence and disease progression after completion of vaccine administration, and four are currently alive (Table II). OS at 2 years after the operation was $62.5 \pm 17.1 \%(95 \%$ confidence interval=22.9-86.1\%).

Analysis of WT1-specific CTLs before and after administration of WT1-DC vaccine. ELISPOT assays were performed for all eight patients. WT1-specific CTLs were evaluated in five out of the eight patients using tetramer analysis before and after administration of the vaccine. Although no significant immunological responses were detected before administration of the vaccine, positive results in WT1-specific CTLs in tetramer assay or ELISPOT were detected after vaccine administration in seven of the eight patients (Tables II, Figure 1). Statistical analysis showed no significant difference in the tetramer assay results before and after WT1-DC vaccination in five patients $(p=0.1250)$. On the other hand, a significant rise in score was observed on comparison of ELISPOT assay results for all patients $(p=0.0156)$. One patient (no. 5) without any WT1-specific immune response showed rapid recurrence of pancreatic cancer and died at 330 days. The analysis results of WT1-specific CTLs in all patients in each clinical course are shown in Figure 2. Although several differences were noted in each clinical course, WT1-specific CTLs were confirmed more than once in patients who lived more than 2 years after surgery. Although we had a limited number of patients, OS at 2 years after surgery was significantly better in patients with immunological response than in nonresponders $(71.4 \%$ vs. $0.0 \%, p=0.008)$. 
Table I. Clinical characteristics of patients treated with the Wilms' tumor 1(WT1)-pulsed dendrititic cell (DC) vaccine after pancreatic cancer resection.

\begin{tabular}{|c|c|c|c|c|c|c|c|c|c|c|c|c|}
\hline \multirow[t]{2}{*}{$\begin{array}{l}\text { Patient } \\
\text { no. }\end{array}$} & \multirow[t]{2}{*}{$\begin{array}{c}\text { Age } \\
\text { (years) }\end{array}$} & \multirow[b]{2}{*}{ Gender } & \multicolumn{2}{|c|}{$\begin{array}{c}\text { Pre-DC vaccination } \\
\text { status }\end{array}$} & \multicolumn{6}{|c|}{ HLA typing } & \multicolumn{2}{|c|}{$\begin{array}{l}\text { IHC for primary } \\
\text { tumor samples }\end{array}$} \\
\hline & & & Stage & Chemotherapy & & A & & & & & WT1 & HLA \\
\hline 1 & 37 & $\mathrm{~F}$ & III & S-1 & 2402 & - & 0901 & - & 0501 & - & $1+$ & $2+$ \\
\hline 2 & 65 & $\mathrm{~F}$ & $\mathrm{IIb}$ & S-1 & 0206 & 1101 & 0405 & 0901 & 0201 & - & $1+$ & $1+$ \\
\hline 3 & 57 & M & $\mathrm{IIb}$ & S-1 & 2402 & 0206 & 0901 & 1454 & 0501 & 0901 & $1+$ & $2+$ \\
\hline 4 & 66 & M & III & S-1 & 2402 & - & 0101 & 1502 & 0402 & 1301 & $2+$ & $2+$ \\
\hline 5 & 57 & M & III & S-1 & 2402 & - & 1502 & 0802 & 0501 & 0901 & $1+$ & $3+$ \\
\hline 6 & 60 & M & IIa & S-1 & 2402 & 0201 & 0403 & 0803 & 0501 & - & $1+$ & $3+$ \\
\hline 7 & 55 & M & III & S-1 + GEM & 2601 & 3101 & 1403 & 1405 & 0202 & 0501 & $1+$ & $3+$ \\
\hline 8 & 62 & M & III & S-1 & 2601 & - & 0406 & 0803 & 0201 & 0501 & $2+$ & $3+$ \\
\hline
\end{tabular}

D: Dendritic cell; F, female; GEM, gemcitabine; HLA: human leukocyte antigen, IHC, immunohistochemistry; M, male.

Table II. Vaccine implementation details and results of Wilms' tumor 1 (WT1)-pulsed dendrititic cell (DC) vaccine in each case.

\begin{tabular}{|c|c|c|c|c|c|c|c|c|c|c|}
\hline \multirow[t]{2}{*}{$\begin{array}{l}\text { Patient } \\
\text { no. }\end{array}$} & \multicolumn{2}{|c|}{$\begin{array}{c}\mathrm{DC} \\
\text { vaccination }\end{array}$} & \multicolumn{2}{|c|}{$\begin{array}{l}\text { Adverse } \\
\text { effects* }\end{array}$} & \multicolumn{2}{|c|}{$\begin{array}{l}\text { Immunological } \\
\text { responses }\end{array}$} & \multicolumn{2}{|c|}{$\begin{array}{c}\text { RECIST } \\
\text { criteria }\end{array}$} & \multirow{2}{*}{$\begin{array}{c}\text { Survival } \\
\text { Duration after } \\
\text { surgery (days) }\end{array}$} & \multirow[t]{2}{*}{ Outcome } \\
\hline & $\begin{array}{l}\text { Total no. of } \\
\text { DCs }\left(\times 10^{7}\right)\end{array}$ & $\begin{array}{l}\text { Total dose of } \\
\text { OK-432 (KE) }\end{array}$ & $\begin{array}{c}\text { Injection-site } \\
\text { reaction (grade) }\end{array}$ & $\begin{array}{l}\text { Fever } \\
\text { (grade) }\end{array}$ & ELISPOT & Tetramer & $\begin{array}{l}\text { At } 1 \\
\text { year }\end{array}$ & $\begin{array}{l}\text { At } 2 \\
\text { years }\end{array}$ & & \\
\hline 1 & 25.1 & 12 & I & 0 & + & + & SD & $\mathrm{NE}$ & 662 & Dead \\
\hline 2 & 11.3 & 12 & I & I & + & $\mathrm{NE}$ & $\mathrm{SD}$ & PD & 1301 & Dead \\
\hline 3 & 22.5 & 13 & I & I & + & + & $\mathrm{SD}$ & PD & $>1393$ & Alive \\
\hline 4 & 27.8 & 7 & I & 0 & + & + & PD & PD & $>930$ & Alive \\
\hline 5 & 19.7 & 7 & I & I & - & - & $\mathrm{NE}$ & $\mathrm{NE}$ & 330 & Dead \\
\hline 6 & 18.3 & 7 & I & I & + & + & $\mathrm{SD}$ & PD & $>826$ & Alive \\
\hline 7 & 22.6 & 13 & I & 0 & + & $\mathrm{NE}$ & $\mathrm{PD}$ & $\mathrm{NE}$ & 508 & Dead \\
\hline 8 & 26.0 & 13 & I & I & + & $\mathrm{NE}$ & $\mathrm{SD}$ & SD & $>782$ & Alive \\
\hline
\end{tabular}

DC(s), Dendrititic cell(s); ELISPOT, enzyme-linked immunospot assay; NE, not evaluated; PD, progressive disease; RECIST: Response Evaluation Criteria in Solid Tumors (30); SD, stable disease. *According to the Common Terminology Criteria for Adverse Events version 4.0 (29).

Immunohistochemical analysis of the primary tumor samples. Expression of WT1 and HLA-ABC were confirmed in the surgical specimens of all the eight patients with pancreatic cancer (Table I). The immunohistochemical analysis findings of two patients (patient 4 and 6) are shown in Figure 3. Table IV shows the results of immunohistochemical analysis of available samples from 34 cases of pancreatic cancer that were treated with the WT1-DC vaccine in our institution. Although WT1 and HLA-ABC in pancreatic cancer cells showed different degrees of expression, expression was confirmed in all the cases. EMA and TAP1 were highly expressed in most cases (Table IV). In addition, no staining was observed in any sample stained with the non-reactive mouse IgG (negative control).

\section{Discussion}

We demonstrated the safety of the WT1-DC vaccine combined with chemotherapy, mainly involving S-1 and adjuvant $\mathrm{OK}-432$, after resection in patients with an initial diagnosis of pancreatic cancer. The adverse events only included reactions at the injection site and fever. Thus, it was possible to complete the scheduled administrations of the vaccine in all the patients. WT1 was highly and frequently expressed, and thus can be an immunotherapy target for pancreatic cancer (9).

Cancer cells can evade immune recognition and destruction through loss or down-regulation of the expression of antigen-processing and antigen-presenting 
(A)

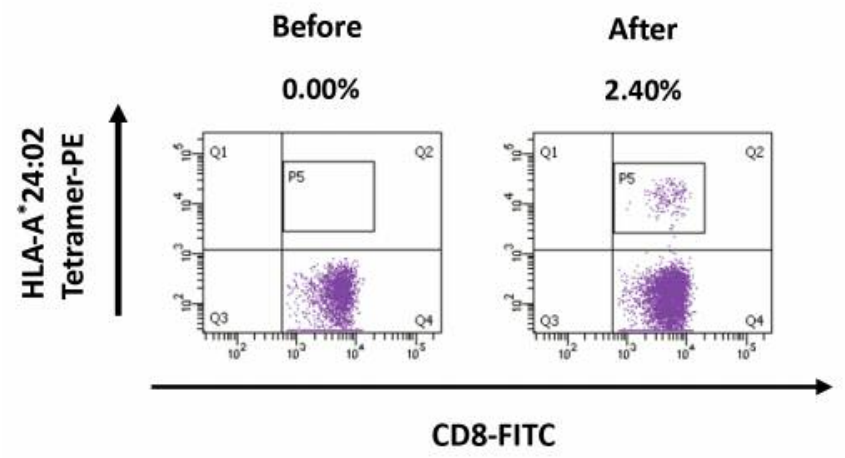

(C)

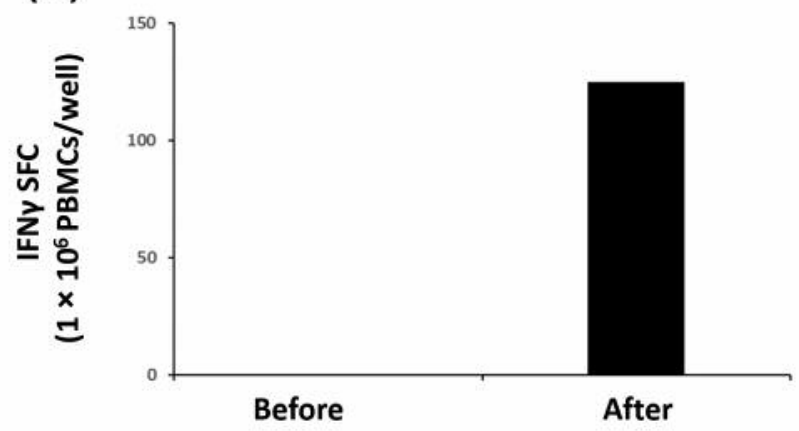

(B)

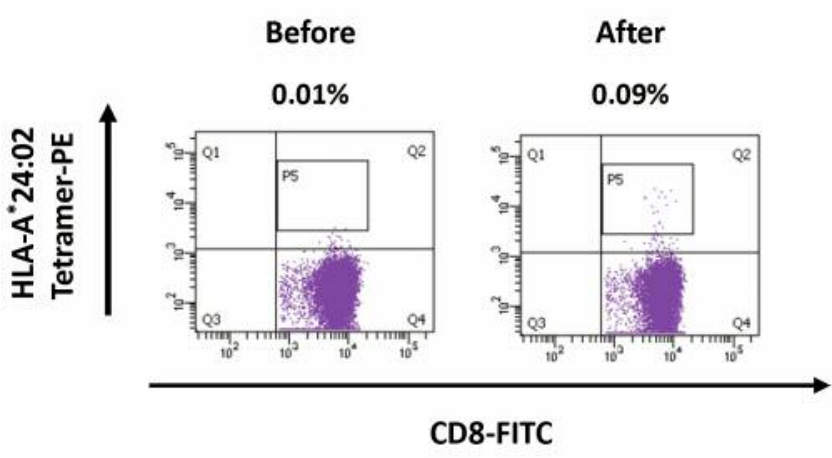

(D)

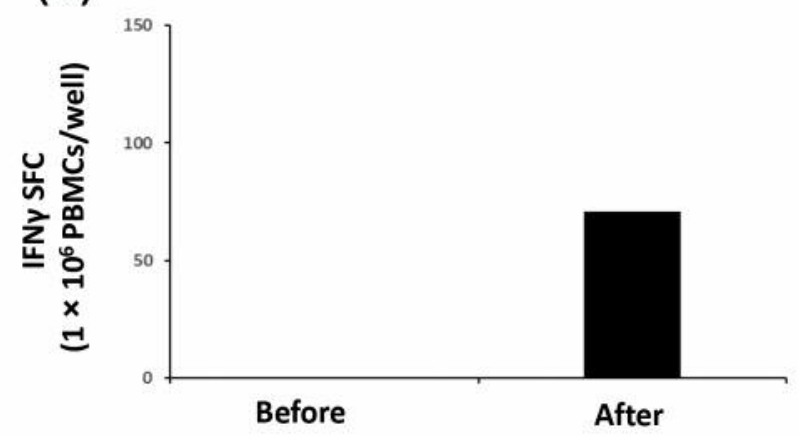

Figure 1. Results of immunological evaluation in two of eight patients (patient 4 and 6). A, B: Analysis of Wilms' tumor 1 (WT1)-specific cytotoxic T-lymphocytes (CTLs) before and after administration of the WT1-peptide pulsed dendritic cell (WT1-DC) vaccine using the WT1 tetramer assay for each patient. C, D: Analysis of WT1-specific CTLs before and after administration of the WT1-DC vaccine using enzyme-linked immunosorbent spot (ELISPOT) assay in each patient. Interferon- $\gamma$ (IFN $)$ spot-forming cells (SFC) are shown after subtraction of the control analysis of peripheral blood mononuclear cells (PBMCs) without addition of WT1 peptide. Each score is shown as the mean of duplicated wells in each analysis. FITC: Fluorescein isothiocyanate label; PE: phycoerythrin label; HLA: human leukocyte antigen.

Table III. Evaluation of Wilms' tumor 1 (WT1)-specific cytotoxic T-lymphocytes before and after WT1-peptide pulsed dendrititic cell (WT1-DC) vaccine treatment. Although enzyme-linked immunospot (ELISPOT) assays were performed in all cases, the WT1-tetramer assay was performed only in patients expressing human leukocyte antigen (HLA)-A*24:02. The results of the ELISPOT are presented as the number of positive spots of WT1-specific interferon gamma production in peripheral blood mononuclear cells (PBMCs) per $10^{6}$ cells. The score is the result of subtraction of the control analysis of PBMCs without addition of WT1 peptide from that of PBMCs with peptide. Each score is shown as the mean of duplicate wells in each analysis. The results of the WT1-tetramer assay are given as the percentage of WT1-specific CD $8^{+}$T-cells in PBMCs. Immunological evaluation was performed based on the previous reports $(27,28)$.

\begin{tabular}{|c|c|c|c|c|c|c|}
\hline \multirow[t]{2}{*}{ Patient number } & \multicolumn{3}{|c|}{ ELISPOT } & \multicolumn{3}{|c|}{ WT1 tetramer } \\
\hline & $\begin{array}{c}\text { Before } \\
\text { vaccination }\end{array}$ & $\begin{array}{c}\text { After } \\
\text { vaccination }\end{array}$ & $\begin{array}{l}\text { Immunological } \\
\text { evaluation }\end{array}$ & $\begin{array}{c}\text { Before } \\
\text { vaccination }\end{array}$ & $\begin{array}{c}\text { After } \\
\text { vaccination }\end{array}$ & $\begin{array}{c}\text { Immunological } \\
\text { evaluation }\end{array}$ \\
\hline 1 & 1 & 10040 & + & $0.01 \%$ & $13.20 \%$ & + \\
\hline 2 & 0 & 195 & + & $\mathrm{NE}$ & $\mathrm{NE}$ & $\mathrm{NE}$ \\
\hline 3 & 1 & 22 & + & $0.00 \%$ & $0.13 \%$ & + \\
\hline 4 & 0 & 125 & + & $0.00 \%$ & $2.40 \%$ & + \\
\hline 5 & 8 & 1 & - & $0.01 \%$ & $0.00 \%$ & - \\
\hline 6 & 0 & 71 & + & $0.01 \%$ & $0.09 \%$ & + \\
\hline 7 & 2 & 4095 & + & $\mathrm{NE}$ & $\mathrm{NE}$ & $\mathrm{NE}$ \\
\hline 8 & 2 & 18 & + & $\mathrm{NE}$ & $\mathrm{NE}$ & $\mathrm{NE}$ \\
\hline
\end{tabular}

NE, Not evaluated. 
Table IV. Immunohistochemical analysis of Wilms' tumor 1 (WT1) and antigen presentation-related molecules in 34 pancreatic cancer cases.

\begin{tabular}{|c|c|c|c|c|c|c|c|c|}
\hline \multirow[t]{2}{*}{ Score of IHC } & \multicolumn{2}{|c|}{ WT1 } & \multicolumn{2}{|c|}{ HLA-ABC } & \multicolumn{2}{|c|}{ TAP1 } & \multicolumn{2}{|c|}{ EMA } \\
\hline & No. of patients & Frequency & No. of patients & Frequency & No. of patients & Frequency & No. of patients & Frequency \\
\hline $3+$ & 0 & $0.0 \%$ & 10 & $29.4 \%$ & 3 & $8.8 \%$ & 27 & $79.4 \%$ \\
\hline $2+$ & 6 & $17.6 \%$ & 19 & $55.9 \%$ & 20 & $58.8 \%$ & 5 & $14.7 \%$ \\
\hline $1+$ & 28 & $82.4 \%$ & 5 & $14.7 \%$ & 11 & $32.4 \%$ & 1 & $2.9 \%$ \\
\hline 0 & 0 & $0.0 \%$ & 0 & $0.0 \%$ & 0 & $0.0 \%$ & 1 & $2.9 \%$ \\
\hline
\end{tabular}

EMA, Epithelial membrane antigen; HLA, human leukocyte antigen; IHC, immunohistochemistry; TAP1, transporter associated with antigen processing 1.

molecules, such as class I and TAP $(33,34)$. Therefore, the application of TAA peptide-specific CTL-based immunotherapy for cancer is thought to be difficult. However, as the expression of HLA molecules is maintained in pancreatic cancer, CTL therapy targeting various TAA factors, including WT1, is considered a promising method for treating pancreatic cancer.

It was possible to confirm the immunological response using WT1-specific CTLs in seven of the eight patients in our study. To date, the use of peptide vaccines has been convenient, but there have been concerns about their efficiency with regard to immunological induction. On the other hand, DCs have a strong antigen-presenting ability, and it is expected that cancer-specific CTLs can be induced more efficiently when DCs pulsed with several TAAs are used as a vaccine $(1,7)$. Although the presence of TAAspecific CTLs cannot guarantee the efficacy of immunotherapy, it is desirable that a high rate of immunity acquisition is assured in patients who receive treatment. As this verification was performed in a limited number of cases, the immunologically induced efficiency of the vaccine for resected pancreatic cancer should be further verified in the future.

Although positive results were obtained with regard to safety and induction efficiency of WT1-specific CTLs in this study, progress of the disease state was inevitable in many cases, and further therapeutic strategies should be devised. To date, studies have been conducted for the use of gemcitabine and DC vaccine therapy for advanced pancreatic cancer $(13,14,16)$. Gemcitabine administration leads to increased expression of WT1 in pancreatic cancer cells (35) and enhances the efficacy of DC-based immunotherapy (36, 37). Additionally, the combined use of gemcitabine and DC therapy may have synergistic effects $(13,14,16)$. Although the use of chemotherapy, including S-1, and WT1-DC vaccines for advanced pancreatic cancer has been reported $(11,12)$, the effectiveness of this combination therapy remains unknown. Recently, a prospective study reported that the prognosis for advanced pancreatic cancer improves

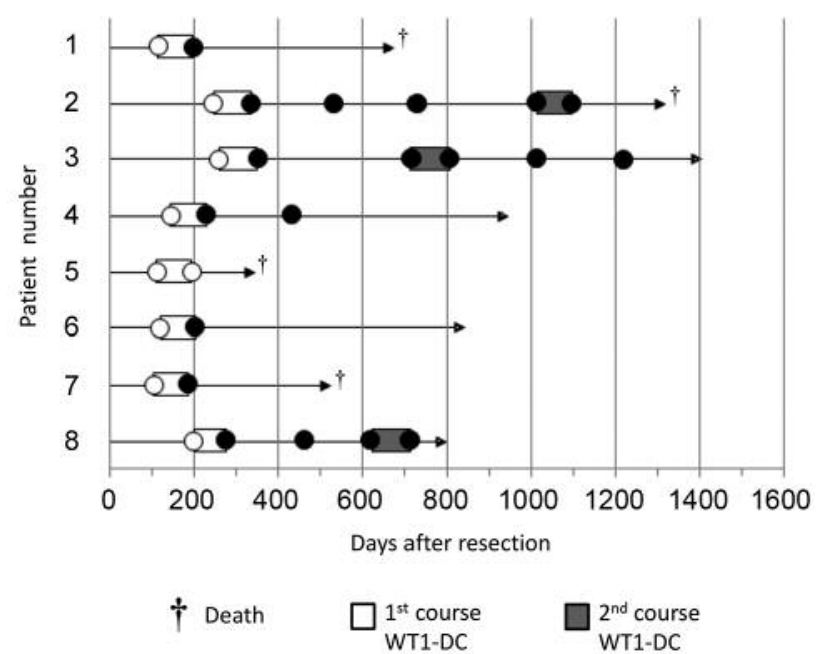

Figure 2. Clinical information regarding the analysis of Wilms' tumor 1 (WT1)-specific immunological responses and outcomes after the resection of pancreatic cancer. Numbers indicate all patients listed in Table I. Each rectangle indicates the periods of WT1-pulsed dendritic cell (WT1-DC) vaccination. Three out of the eight patients received the second course of WT1-DC vaccination (patient 2, 3, and 8). The WT1specific immunological responses in each patient's clinical course are also shown. White circles indicate negative response. Black circles indicate positive response for the analysis of WT1-specific cytotoxic Tlymphocytes (CTLs) using the WT1 tetramer assay and/or enzyme-linked immunosorbent spot (ELISPOT).

with the use of immunotherapy involving DCs and cytokineinduced killer cells administered with S-1 (38), thus suggesting the synergistic efficacy of S-1 therapy combined with immunotherapy. For resected pancreatic cancer, S-1 has better efficacy in preventing recurrence than that of gemcitabine (25). The use of immunotherapy, including the WT1-DC vaccine, may be another treatment option in the future. Furthermore, in recent years, therapy targeting various factors has been examined for pancreatic cancer (2, 5); thus, combinations of our approach with new treatment modalities might be considered. 


\section{Patient 4}
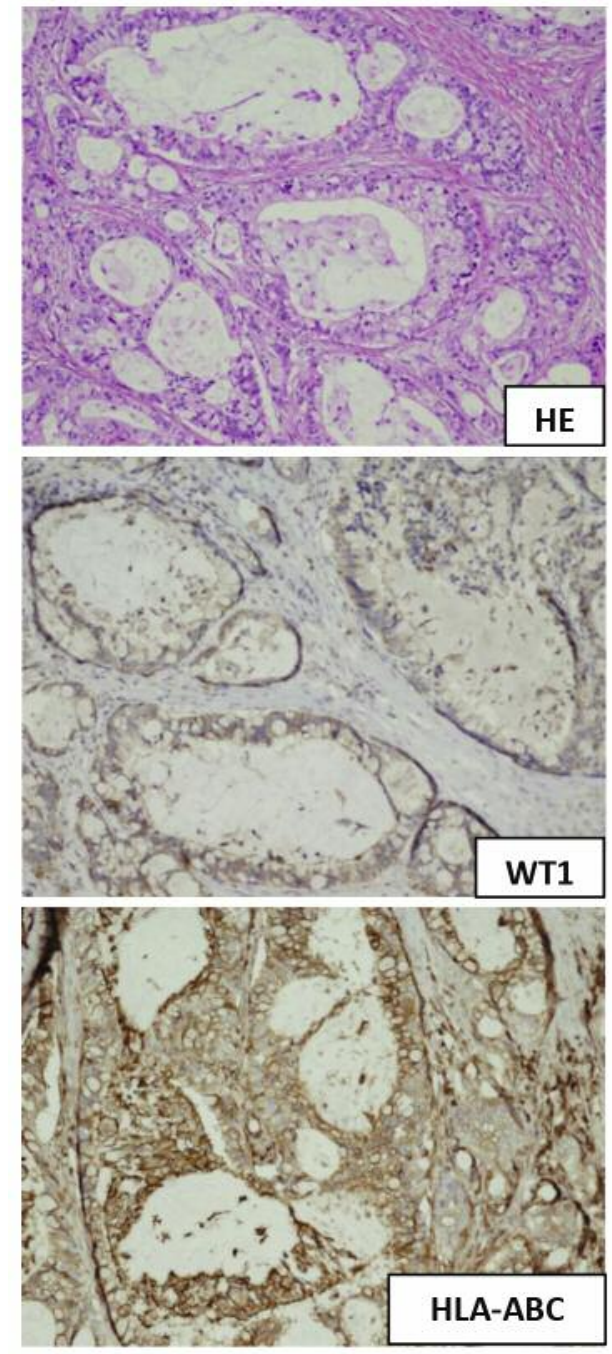

Patient 6
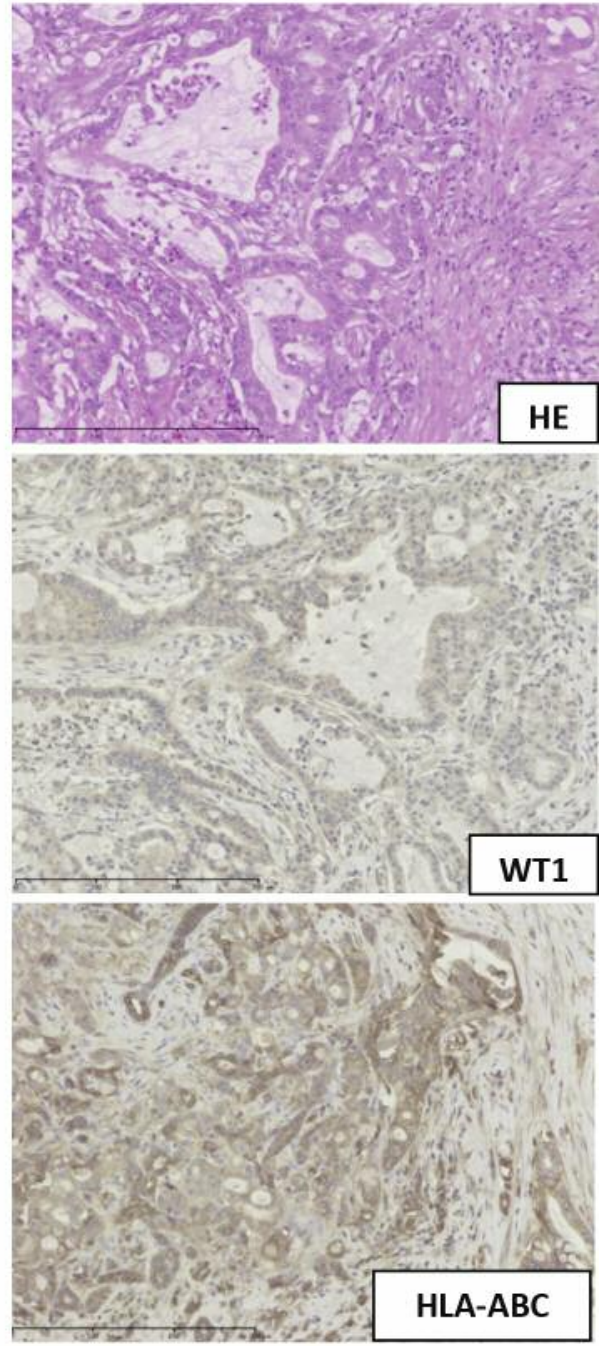

Figure 3. Results of immunohistochemical analysis of the primary tumor samples in two out of eight patients (patient 4 and 6). Hematoxylin and eosin (HE), human leukocyte antigen (HLA)-ABC, and Wilms' tumor 1 (WT1) staining of each patient's samples are shown.

A phase I study that evaluated WT1-DC vaccination in combination with chemotherapy (S-1) in patients with resected pancreatic cancer demonstrated its safety and immunogenicity as an adjuvant setting. Prospective clinical trials are required for evaluating the efficacy of the immunity acquired in response to adjuvant WT1-DC vaccination in improving the prognosis of pancreatic cancer. On the basis of the results of our pilot study, we plan to continue the designated phase II clinical trials in patients with resected pancreatic cancer.

\section{Future Prospects}

We are preparing an advanced WT1-DC vaccine for the treatment of resected pancreatic cancer under a clinical trial (covered by
Advanced Medical Care System; investigator-initiated clinical trial) using WT1 peptide and DC manufacturing according to the standard grade of Good Gene, Cellular, and Tissue-based Products.

\section{Conflicts of Interests}

The Authors declare no potential conflicts of interest exist in regard to this study.

\section{Additional Information}

H. Sugiyama is the inventor of patents PCT/JP02/02794 and PCT/JP04/16336 which are held by the International Institute of Cancer Immunotherapy. 


\section{Acknowledgements}

The Authors thank Ms. Yumiiko Higuchi, Mr. Shinsuke Ishikawa, Ms. Naoko Yamaoka and Ms. Yumiko Mizuno for supporting the immunological analysis. This work was supported by JSPS KAKENHI Grant Number 16K10021.

\section{References}

1 Koido S, Okamoto M, Kobayashi M, Shimodaira S and Sugiyama H: Significance of Wilms' tumor 1 antigen as a cancer vaccine for pancreatic cancer. Discov Med 24: 41-49, 2017.

2 Kotteas E, Saif MW and Syrigos K: Immunotherapy for pancreatic cancer. J Cancer Res Clin Oncol 142: 1795-1805, 2016.

3 Mizuguchi T, Torigoe T, Satomi F, Shima H, Kutomi G, Ota S, Ishii M, Hayashi H, Asakura S, Hirohashi Y, Meguro M, Kimura Y, Nishidate T, Okita K, Ishino M, Miyamoto A, Hatakenaka M, Sato $\mathrm{N}$ and Hirata K: Trials of vaccines for pancreatic ductal adenocarcinoma: Is there any hope of an improved prognosis? Surg Today 46: 139-148, 2016.

4 Saung MT and Zheng L: Current standards of chemotherapy for pancreatic cancer. Clin Ther 39: 2125-2134, 2017.

5 Foley K, Kim V, Jaffee E and Zheng L: Current progress in immunotherapy for pancreatic cancer. Cancer Lett 381: 244-251, 2016.

6 Kajihara M, Takakura K, Kanai T, Ito Z, Matsumoto Y, Shimodaira S, Okamoto M, Ohkusa T and Koido S: Advances in inducing adaptive immunity using cell-based cancer vaccines: Clinical applications in pancreatic cancer. World J Gastroenterol 22: 4446-4458, 2016.

7 Koido S, Okamoto M, Shimodaira S and Sugiyama H: Wilms' tumor 1 (WT1)-targeted cancer vaccines to extend survival for patients with pancreatic cancer. Immunotherapy 8: 1309-1320, 2016.

8 Sugiyama H: WT1 (Wilms' tumor gene 1): biology and cancer immunotherapy. Jpn J Clin Oncol 40: 377-387, 2010.

9 Oji Y, Nakamori S, Fujikawa M, Nakatsuka S, Yokota A, Tatsumi N, Abeno S, Ikeba A, Takashima S, Tsujie M, Yamamoto H, Sakon M, Nezu R, Kawano K, Nishida S, Ikegame K, Kawakami M, Tsuboi A, Oka Y, Yoshikawa K, Aozasa K, Monden M and Sugiyama H: Overexpression of the Wilms' tumor gene WT1 in pancreatic ductal adenocarcinoma. Cancer Sci 95: 583-587, 2004.

10 Kaida M, Morita-Hoshi Y, Soeda A, Wakeda T, Yamaki Y, Kojima Y, Ueno H, Kondo S, Morizane C, Ikeda M, Okusaka T, Takaue Y and Heike Y: Phase 1 trial of Wilms tumor 1 (WT1) peptide vaccine and gemcitabine combination therapy in patients with advanced pancreatic or biliary tract cancer. J Immunother 34: 92-99, 2011.

11 Kimura Y, Tsukada J, Tomoda T, Takahashi H, Imai K, Shimamura K, Sunamura M, Yonemitsu Y, Shimodaira S, Koido $\mathrm{S}$, Homma $\mathrm{S}$ and Okamoto M: Clinical and immunologic evaluation of dendritic cell-based immunotherapy in combination with gemcitabine and/or S-1 in patients with advanced pancreatic carcinoma. Pancreas 41: 195-205, 2012.

12 Kobayashi M, Shimodaira S, Nagai K, Ogasawara M, Takahashi H, Abe H, Tanii M, Okamoto M, Tsujitani S, Yusa S, Ishidao T, Kishimoto J, Shibamoto Y, Nagaya M and Yonemitsu Y: Prognostic factors related to add-on dendritic cell vaccines on patients with inoperable pancreatic cancer receiving chemotherapy: a multicenter analysis. Cancer Immunol Immunother 63: 797-806, 2014.
13 Koido S, Homma S, Okamoto M, Takakura K, Mori M, Yoshizaki S, Tsukinaga S, Odahara S, Koyama S, Imazu H, Uchiyama K, Kajihara M, Arakawa H, Misawa T, Toyama Y, Yanagisawa S, Ikegami M, Kan S, Hayashi K, Komita H, Kamata Y, Ito M, Ishidao T, Yusa S, Shimodaira S, Gong J, Sugiyama H, Ohkusa T and Tajiri H: Treatment with chemotherapy and dendritic cells pulsed with multiple Wilms' tumor 1 (WT1)-specific MHC class I/II-restricted epitopes for pancreatic cancer. Clin Cancer Res 20: 4228-4239, 2014.

14 Mayanagi S, Kitago M, Sakurai T, Matsuda T, Fujita T, Higuchi $\mathrm{H}$, Taguchi J, Takeuchi H, Itano O, Aiura K, Hamamoto Y, Takaishi H, Okamoto M, Sunamura M, Kawakami Y and Kitagawa Y: Phase I pilot study of Wilms tumor gene 1 peptidepulsed dendritic cell vaccination combined with gemcitabine in pancreatic cancer. Cancer Sci 106: 397-406, 2015.

15 Nishida S, Koido S, Takeda Y, Homma S, Komita H, Takahara A, Morita S, Ito T, Morimoto S, Hara K, Tsuboi A, Oka Y, Yanagisawa S, Toyama Y, Ikegami M, Kitagawa T, Eguchi H, Wada H, Nagano H, Nakata J, Nakae Y, Hosen N, Oji Y, Tanaka T, Kawase I, Kumanogoh A, Sakamoto J, Doki Y, Mori M, Ohkusa T, Tajiri H and Sugiyama H: Wilms tumor gene (WT1) peptidebased cancer vaccine combined with gemcitabine for patients with advanced pancreatic cancer. J Immunother 37: 105-114, 2014.

16 Takakura K, Koido S, Kan S, Yoshida K, Mori M, Hirano Y, Ito Z, Kobayashi H, Takami S, Matsumoto Y, Kajihara M, Misawa T, Okamoto M, Sugiyama H, Homma S, Ohkusa T and Tajiri H: Prognostic markers for patient outcome following vaccination with multiple MHC Class I/II-restricted WT1 peptide-pulsed dendritic cells plus chemotherapy for pancreatic cancer. Anticancer Res 35: 555-562, 2015.

17 Hailemichael Y, Dai Z, Jaffarzad N, Ye Y, Medina MA, Huang XF, Dorta-Estremera SM, Greeley NR, Nitti G, Peng W, Liu C, Lou Y, Wang Z, Ma W, Rabinovich B, Sowell RT, Schluns KS, Davis RE, Hwu P and Overwijk WW: Persistent antigen at vaccination sites induces tumor-specific CD8(+) T-cell sequestration, dysfunction and deletion. Nat Med 19: 465-472, 2013.

18 Itoh T, Ueda Y, Okugawa K, Fujiwara H, Fuji N, Yamashita T, Fujiki H, Harada S, Yoshimura T and Yamagishi H: Streptococcal preparation OK432 promotes functional maturation of human monocyte-derived dendritic cells. Cancer Immunol Immunother 52: 207-214, 2003.

19 Oshimi K, Kano S, Takaku F and Okumura K: Augmentation of mouse natural killer cell activity by a streptococcal preparation, OK-432. J Natl Cancer Inst 65: 1265-1269, 1980.

20 Saito M, Nanjo M, Aonuma E, Noda T, Nakadate I, Ebina T and Ishida N: Activated macrophages are responsible for the tumorinhibitory effect in mice receiving intravenous injection of OK432. Int J Cancer 33: 271-276, 1984.

21 Saito M, Nanjo M, Kataoka M, Moriya Y, Sugawara Y, Yoshida $\mathrm{T}$ and Ishida $\mathrm{N}$ : Adoptive immunotherapy by pantropic killer cells recovered from OK-432-injected tumor sites in mice. Cancer Res 48: 4163-4167, 1988.

22 Shitara K, Ichimura O, Mitsuno T and Osawa T: Natural killer (NK) cell activating factor released from murine thymocytes stimulated with an anti-tumor streptococcal preparation, OK432. J Immunol 134: 1039-1047, 1985.

23 Wakasugi H, Kasahara T, Minato N, Hamuro J, Miyata M and Morioka Y: In vitro potentiation of human natural killer cell activity by a streptococcal preparation, OK-432: interferon and interleukin-2 participation in the stimulation with OK-432. J Natl Cancer Inst 69: 807-812, 1982. 
24 Hirayama M, Nishikawa H, Nagata Y, Tsuji T, Kato T, Kageyama S, Ueda S, Sugiyama D, Hori S, Sakaguchi S, Ritter G, Old LJ, Gnjatic S and Shiku H: Overcoming regulatory T-cell suppression by a lyophilized preparation of Streptococcus pyogenes. Eur J Immunol 43: 989-1000, 2013.

25 Uesaka K, Boku N, Fukutomi A, Okamura Y, Konishi M, Matsumoto I, Kaneoka Y, Shimizu Y, Nakamori S, Sakamoto H, Morinaga S, Kainuma O, Imai K, Sata N, Hishinuma S, Ojima $\mathrm{H}$, Yamaguchi R, Hirano S, Sudo T and Ohashi Y: Adjuvant chemotherapy of S-1 versus gemcitabine for resected pancreatic cancer: a phase 3, open-label, randomised, non-inferiority trial (JASPAC 01). Lancet 388: 248-257, 2016.

26 Koya T, Yanagisawa R, Higuchi Y, Sano K and Shimodaira S: Interferon-alpha-inducible dendritic cells matured with OK-432 exhibit TRAIL and Fas ligand pathway-mediated killer activity. Sci Rep 7: 42145, 2017.

27 Shimodaira S, Sano K, Hirabayashi K, Koya T, Higuchi Y, Mizuno Y, Yamaoka N, Yuzawa M, Kobayashi T, Ito K and Koizumi T: Dendritic cell-based adjuvant vaccination targeting Wilms' tumor 1 in patients with advanced colorectal cancer. Vaccines 3: 1004-1018, 2015.

28 Sakai K, Shimodaira S, Maejima S, Udagawa N, Sano K, Higuchi Y, Koya T, Ochiai T, Koide M, Uehara S, Nakamura M, Sugiyama H, Yonemitsu Y, Okamoto M and Hongo K: Dendritic cell-based immunotherapy targeting Wilms' tumor 1 in patients with recurrent malignant glioma. J Neurosurg 123: 989-997, 2015.

29 Common Terminology Criteria for Adverse Events (CTCAE) v4.0. Available from http://ctep.cancer.gov/protocol Development/ electronic_applications/ctc.htm\#ctc_40. Last accessed Febrary 20, 2018.

30 Eisenhauer EA, Therasse P, Bogaerts J, Schwartz LH, Sargent D, Ford R, Dancey J, Arbuck S, Gwyther S, Mooney M, Rubinstein L, Shankar L, Dodd L, Kaplan R, Lacombe D, and Verweij J: New response evaluation criteria in solid tumours: revised RECIST guideline (version 1.1). Eur J Cancer 45: 228247, 2009.

31 Foster MR, Johnson JE, Olson SJ and Allred DC: Immunohistochemical analysis of nuclear versus cytoplasmic staining of WT1 in malignant mesotheliomas and primary pulmonary adenocarcinomas. Arch Pathol Lab Med 125: 1316-1320, 2001.
32 Kanda Y: Investigation of the freely available easy-to-use software 'EZR' for medical statistics. Bone Marrow Transplant 48: 452-458, 2013.

33 Hicklin DJ, Marincola FM and Ferrone S: HLA class I antigen down-regulation in human cancers: T-cell immunotherapy revives an old story. Mol Med Today 5: 178-186, 1999.

34 Pandha H, Rigg A, John J and Lemoine N: Loss of expression of antigen-presenting molecules in human pancreatic cancer and pancreatic cancer cell lines. Clin Exp Immunol 148: 127-135, 2007.

35 Takahara A, Koido S, Ito M, Nagasaki E, Sagawa Y, Iwamoto T, Komita H, Ochi T, Fujiwara H, Yasukawa M, Mineno J, Shiku H, Nishida S, Sugiyama H, Tajiri H and Homma S: Gemcitabine enhances Wilms' tumor gene WT1 expression and sensitizes human pancreatic cancer cells with WT1-specific T-cellmediated antitumor immune response. Cancer Immunol Immunother 60: 1289-1297, 2011.

36 Pei Q, Pan J, Zhu H, Ding X, Liu W, Lv Y, Zou X and Luo H: Gemcitabine-treated pancreatic cancer cell medium induces the specific CTL antitumor activity by stimulating the maturation of dendritic cells. Int Immunopharmacol 19: 10-16, 2014.

37 Soeda A, Morita-Hoshi Y, Makiyama H, Morizane C, Ueno H, Ikeda M, Okusaka T, Yamagata S, Takahashi N, Hyodo I, Takaue $Y$ and Heike Y: Regular dose of gemcitabine induces an increase in $\mathrm{CD} 14^{+}$monocytes and $\mathrm{CD} 11 \mathrm{c}^{+}$dendritic cells in patients with advanced pancreatic cancer. Jpn J Clin Oncol 39: 797-806, 2009.

38 Jiang N, Qiao G, Wang X, Morse MA, Gwin WR, Zhou L, Song Y, Zhao Y, Chen F, Zhou X, Huang L, Hobeika A, Yi X, Xia X, Guan Y, Song J, Ren J and Lyerly HK: Dendritic cell/cytokineinduced killer cell immunotherapy combined with $\mathrm{S}-1$ in patients with advanced pancreatic cancer: a prospective study. Clin Cancer Res 23: 5066-5073, 2017.
Received January 16, 2018

Revised February 13, 2018

Accepted February 21, 2018 